\title{
EVALUATION OF RESORBABLE PLATES WITH ULTRASONIC WELDED PINS IN THE MANAGEMENT OF MIDFACE FRACTURES (CLINICAL, HISTOLOGICAL, AND BIOMECHANICAL STUDY)
}

\author{
Ahmed O. Sweedan ${ }^{l}$ M.Sc, Nagy E. Hassan ${ }^{2} P h D$, Samraa A. El-Sheikh ${ }^{2} P h D$, \\ Riham M. El-Dibany ${ }^{2} P h D$, Khadiga Y. Kawana ${ }^{3} P h D$
}

\begin{abstract}
INTRODUCTION: The use of biodegradable screws has a number of limiting factors including poor mechanical stability, difficult handling properties, and time-consuming fixation. A new application system by welding a special configured resorbable pin through ultrasound may overcome the disadvantages of thread tapping.

OBJECTIVES: Was to evaluate resorbable plates with ultrasonic welded pins in management of midface fracture.

MATERIALS AND METHODS: Was conducted clinically on 20 midface fracture cases fixed with resorbable plates with ultrasonic welded pins, histologically on 4 healthy adult mongrel dogs, and biomechanically on 15 specimens tested for tension, bending, and torsion stiffness of this system.

RESULTS: Clinically intraoperative handling showed $13 \%$ failure rate for the total number of pins placed for all cases, with stability failure in $10 \%$ of cases, and mean time needed for fixation of each plate was 10.6 minutes, however postoperative clinical results were normal with no significant complications. Radiographically; adequate bone healing with delayed resorption of pins was observed during follow-up phase which was continued till $12^{\text {th }}$ week postoperatively. Histological study revealed woven bone growing in the defect area and development of new bone, osteocytes and osteoblasts seen on bone surface. Biomechanical study showed mean tensile stiffness $498.982 \mathrm{~N} / \mathrm{mm}$ while mean bending stiffness was $1.176 \mathrm{~N} / \mathrm{mm}$ and mean torsion stiffness was $0.342 \mathrm{~N} / \mathrm{mm}$.

CONCLUSIONS: This retrospective study shows the general feasibility, sufficient mechanical stability, and efficient intraoperative handling of resorbable plates with ultrasonic welded pins in management of midface fractures.

KEY WORDS: Resorbable plate, Ultrasound welded pin, Midface fracture, SonicWeld Rx

1- Assistant lecturer at Oral and Maxillofacial Surgery Department, Faculty of Dentistry, Alexandria University.

2- Professor of Oral and Maxillofacial Surgery, Department of Oral and Maxillofacial Surgery, Faculty of Dentistry, Alexandria University.

3- Professor of Oral Biology, Department of Oral Biology, Faculty of Dentistry, Alexandria University.
\end{abstract}

\section{INTRODUCTION}

Different osteosynthesis systems are used to reconstruct the facial skeleton according to the highly variable cranial bony structures (1).

Removal of the osteosynthesis material may be necessary for screw and plate loosening or palpations under tender skin and discomfort of the patient in the midface. Also, the plates and screws may cause imaging artifacts in computed tomography $(\mathrm{CT})(2,3)$.

Titanium osteosynthesis plates are only necessary for the stabilization of the fracture and during the healing period. After this period the plates and screws can be removed. Resorbable osteosynthesis materials may avoid these shortcomings of the titanium osteosynthesis material (4).

Mechanical stability as well as handling is a limitation of their application in trauma treatment in the face. Therefore, resorbable osteosynthesis materials are primarily recommended for anatomical areas with minor mechanical load (5).

Most common raw materials for the fabrication of biodegradable materials are polymers and copolymers of glycolicacid (polyglycolid, PGA), lactic acid (polylactid, PLA), and mixtures of D- and L-lactides (PDLLA) The biodegradation of resorbable osteosynthesis depends on 2 main factors: the composition of the material itself and the surrounding tissue. The manufactured combination determines the properties as biomechanical stability and biochemical decomposition of the osteosynthesis plates (6).
Complications that have to be considered with biodegradable materials are soft tissue swelling, foreign body reactions, sterile fistulas, and osteolysis. A crucial criterion for the application of resorbable plates and screws in craniomaxillofacial surgery is their mechanical stability at least for the duration of 10 weeks, during the time of fracture healing. The required heat activating process and the thread-tapping can especially hamper the surgical workflow $(7,8)$.

Fixation of the plates with resorbable screws requires tapping a thread. This makes the application of resorbable plates very difficult, especially in the thin bone of the midface. To avoid this additional step would improve and facilitate the application of a resorbable system (9).

The use of biodegradable screws has a number of limiting factors: poor mechanical stability, difficult handling properties, and time-consuming fixation. The tapping of threads takes a long time and limits easy handling, particularly for small diameter screws, and the insertion is limited by the relation of the axis of the screw to the osteosynthesis plate $(10,11)$.

Insufficient fracture stabilization, especially at the infraorbital rim and the zygomaticomaxillary crest/anterior sinus wall, was the main reason to switch to titanium osteosynthesis. The biodegradable screw design is possibly too bulky for these particular bony structures (12).

A new application system by welding a special configured resorbable pin though ultrasound may overcome 
the disadvantages of thread tapping. With the advantage of only a 2-step procedure, without cutting a thread into the bone the resorbable pin is welded in the corticospongy structure of the bone, using an ultrasonic tool. The resorbable plates and pins are commercial products and consist of an amorphous Poly (D-L-) lactide (13).

Further, Cho et al (14) in 2011 stated that Sonic-Weld fixation can withstand similar load forces as titanium screw fixation. This technique was employed for the full spectrum of heterogeneous movements. Along these lines, pilling et al (15) in 2007 demonstrated with an in vivo sheep model that overall mechanical stability of the ultrasound welded pin osteosynthesis was superior to conventional resorbable screw osteosynthesis.

We report on the application of this new resorbable system (SonicWeld Rx by KLS Martin, Tuttlingen, Germany) for the treatment of midface fracture. Our documentation comprises intraoperative handling, mechanical aspects, and histological examination of the interactions between the material and the bone.

\section{MATERIALS AND METHODS}

\section{Study design:}

This study was performed on clinical, histological, and biomechanical trials. The clinical and histological parts of this study were performed after the approval of research ethics committee, Faculty of Dentistry, Alexandria University.

\section{I- Clinical study:}

This clinical trial was conducted on 20 patients suffering from midface fracture selected from the Emergency Room of the In-Patient Clinic of the Oral and Maxillofacial Surgery Department, Faculty of Dentistry, Alexandria University. All patients of this study were treated using resorbable plates with ultrasound activated pin osteosynthesis (SonicWeld Rx). They were included in this study after having signed informed consent.

Inclusion Criteria were; presence of unilateral or bilateral midface fracture, patient's age ranged from 18 to 45 years old, and fracture required open reduction and fixation. Exclusion Criteria were; presence of comminuted fracture, infected fracture site, patients suffered from systemic bone diseases.

\section{Materials:}

Resorbable plates with ultrasound activated pin osteosynthesis (SonicWeld Rx):

Straight 4 holes and 8 holes' biodegradable plates of 1 $\mathrm{mm}$ thickness were used in this study. They are composed of non-crystalline Poly-D-L-lactic acid (PDLLA) that is completely amorphous material consisting of D-lactide and L-lactide (each 50\%).

Resorbable ultrasonic welded pins composed of PDLLA. The SonicPins are available in diameters 1.6 or $2.1 \mathrm{~mm}$ and 5 or $7 \mathrm{~mm}$ length. Pin is translucent with polygonal elevations along its surface to assure friction with bone surface but there are no threads on its surface (Fig. 1). Head of pin is self-retaining by friction-fit so it can be picked up with the sonotrode tip and pushed into predrilled holes with no twisting motion. Pin head merges with the plate and the pin's outer surface penetrates into all bone cavities.

\section{SonicWelder Rx and Sonotrode:}

The core component of this machine is what is referred to as the SonicWelder Rx, an ultrasound generator that is used to generate ultrasonic waves of precisely defined frequency (29.5 kHz, max. power 20 watts) then focused with hand piece called sonotrode (Fig.1). The SonicPin Rx is picked up with the sonotrode tip and placed onto the predrilled hole then slight pressure is maintained forward and the ultrasound generator is activated with a foot switch.

Auxiliary devices included drills of 4,6 , or $8 \mathrm{~mm}$ length, 1 or $1.6 \mathrm{~mm}$ diameter was used to drill the holes needed for pin placement and heater (thermal unit) which is a heating system for the easy contouring of the plates to be adapted to bone surface curvatures.
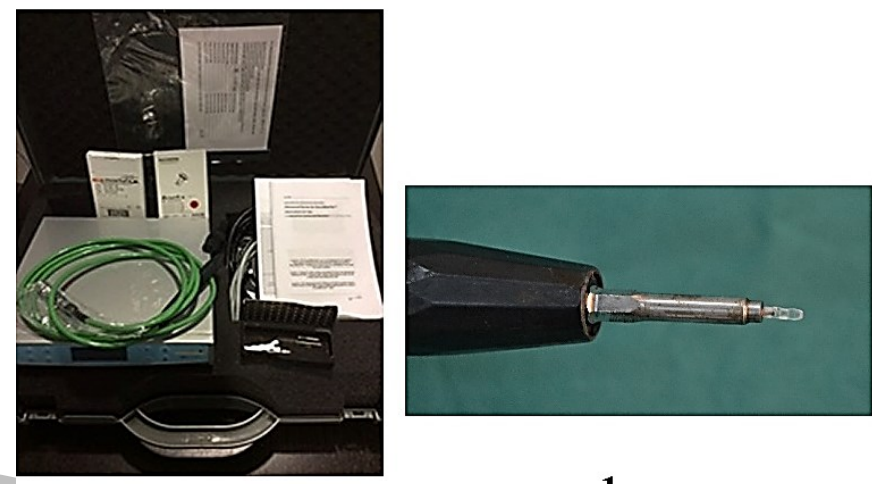

a

Figure (1): a. Sonicwelder and sonotrode. b. SonicPin Rx attached to sonotrode.

\section{Methods:}

\section{A) Pre-operative Phase:}

Comprehensive medical and dental history was collected from all patients including; name, age, gender, occupation, address, date and time of injury, immediate measures taken, and level of consciousness at time of administration.

All patients were subjected to full clinical examination by inspection and palpation of the fracture sites both extraorally and intra-orally to detect the presence of edema, ecchymosis, soft tissue laceration, hemorrhage, site of fracture, dentition, derangement of occlusion, areas of tenderness, step deformities, mobility of fractured segments, ocular mobility, presence of sub conjunctival hemorrhage and damage to the teeth in or around the fracture line. In addition, nerve function, visual disturbances and the presence of associated injuries.

Radiographic examination was accomplished for all patients at the time of presentation. Axial, coronal, 3D reconstruction computerized tomography (CT) was taken for all patients.

\section{B) Operative Phase:}

After preoperative preparations all cases were treated under general anesthesia with nasotracheal intubation or orotracheal intubation. Face was painted with povidoneiodine. The oral cavity was prepared with diluted povidoneiodine. Towels and drapes were applied to expose the surgical area. Local infiltration injection, at all fracture sites except infraorbital rim, was done using $2 \%$ lidocaine with 1:1000 000 adrenalines for vasoconstriction.

Lateral eyebrow or upper blepharoplasty incision was used for fronto-zygomatic region fractures. Subtarsal incision was done for zygomatico-maxillary region and orbital floor. Intraoral upper buccal vestibular incision was used for zygomatic buttress fractures. Coronal flap with preauricular incision was the chosen approach for zygomatic arch and from this approach frontozygomatic region was also exposed. 
Blunt dissection was done in layers and periosteal flap raised in buttress region to expose the fracture site. Great care was taken not to damage involved nerves and vessels at each approach.

Open reduction was done and fracture segments were reduced. In cases of disturbed occlusion, occlusion was established with maxillomandibular fixation before fixation of fractured segments.

For midface fractures fixation resorbable plates with SonicWeld Rx pins were used. The resorbable plates were first preactivated in thermo water bath at $55^{\circ} \mathrm{C}$ for $1-2$ minutes, contoured to the desired shape required, and then adapted against the bone segment. Plates were malleable for 10-15 seconds and then they could be reheated for further contouring or cut once cooled. Pin holes were drilled according to the size of the pin used. Drill length size 4 or $6 \mathrm{~mm}$ for pin 5 or $7 \mathrm{~mm}$ length respectively. Drill diameter $1,1.6 \mathrm{~mm}$ for pin diameter $1.6,2.1 \mathrm{~mm}$ respectively. Using the corresponding drill attached to the hand piece and micromotor holes were done for each hole in the resorbable plate with constant saline irrigation.

The SonicPin Rx was picked up with the sonotrode tip from its color coded clip and placed onto the predrilled hole then slight pressure was maintained forward and the ultrasound generator was activated with its foot switch.

When activating the ultrasound generator, the pin was set vibrating via the sonotrode. The friction between the vibrating pin and the bone surface generated heat, liquefying the pin surface and thus enabling it to glide into the hole. By changing the state of aggregation, the pin even penetrated into bone cavities. In addition, the head of the SonicPin bonded with the plate creating plate-pin complex.

By the start of fixation of each resorbable plate time was calculated using stopwatch from the beginning of preactivation of the plate till the end of placement of last pin.

Fixation was done using 4 holes resorbable plate along each facial buttress for all cases except for zygomatic arch fracture 8 holes resorbable plate was used.

In cases of zygomaticomaxillary complex fracture 2point fixation was done first at the zygomaticofrontal region and infraorbital ridge then the stability of zygomatic bone was examined bimanually to determine the need for a third point of fixation (Fig. 2).

In cases of Le Fort I fixation was done along the zygomaticomaxillary and the nasomaxillary buttresses, while in Le Fort II it was done along infraorbital and zygomaticomaxillary buttresses.

Intraoperative handling evaluation included failure rate of ultrasonic welded pins, time needed for fixation of each plate after proper reduction, stability of the resorbable plate after welding of the pins, and any difficulty during handling the SonicWeld system.

After checking of stability of fractured segment occlusion was rechecked in cases of preoperative occlusal disturbance. Wounds debridement was done using saline irrigation. Closure of extraoral wounds was done in layers using vicryl 3-0 for deep layers and 4-0 proline for skin layer, while intraoral wounds were closed using vicryl 3-0. Extraoral pressure bandages were applied for extraoral wounds.

\section{C) Postoperative Phase:}

Antibiotic schedule, Clindamycin 600mg (Dalacin c phosphate, Upjohn, USA), every 12 hours in addition to anti-inflammatory drug ibuprofen 400mg (Brufen 400, Abbott, India) was continued post-operatively for 72 hours. All patients were advised to stick to postoperative care instructions to prevent postoperative complications. Dressing change was done by nursing staff on daily bases. Occlusion was checked in all cases on the 1 st postoperative day, 3rd postoperative day, and on subsequent visits, and complications were recorded if any. Sutures removed after 5 to 7 days.
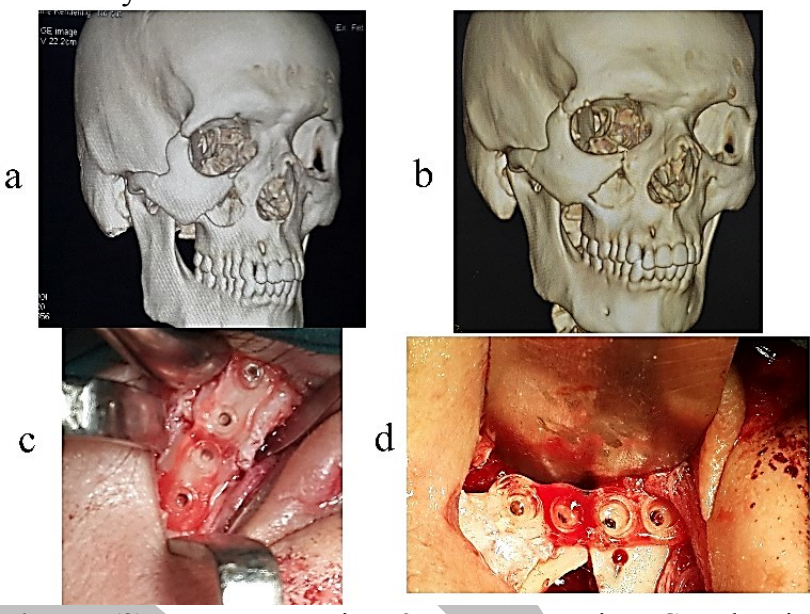

Figure (2): a. Preoperative 3D reconstruction CT showing zygomaticomaxillary complex fracture.

b. Postoperative 3D reconstruction CT showing zygomaticomaxillary complex fracture after reduction and fixation using SonicWeld Rx system.

c. Intraoperative photograph showing properly fixed resorbable plate with sonic welded pins (SonicWeld Rx) at frontozygomatic fracture line.

d. Intraoperative photograph showing properly fixed resorbable plate with sonic welded pins (SonicWeld $\mathrm{Rx}$ ) at infraorbital rim fracture line.

\section{D) Follow-up Phase:}

All cases were clinically examined on the $1 \mathrm{st}$, 3rd, and 6th weeks postoperatively to evaluate presence of edema, presence of infection, degree of pain using the Numeric Rating Scale (NRS-11), Stability of fractured segment examined bimanually, occlusal disturbance, presence of abnormal sensation, and any other clinical findings.

\section{Radiographic evaluation:}

All patients were radiographicaly examined immediately postoperative, the 6 th week, and 12 th week postoperative using computerized tomography (CT).

Housenfield unit (HU) was measured at fracture line gap and at resorbable pins on the CT in order to evaluate bone density at fracture line gap and degree of resorption of SoniPin Rx in both 6th week and 12th week postoperative CT.

\section{STATISTICAL ANALYSIS}

Statistical Package of Social Sciences (version 24.0; SPSS, Chicago, IL) was used to analyze clinical and radiographic data.

Clinical data was analyzed using descriptive statistics Radiographic data was analyzed using paired t-test.

\section{II- Histological study:}

This part of the study was conducted on 4 healthy adult mongrel dogs, 18 to 24 months old, and average weight ranged from 10 to $15 \mathrm{Kg}$ a fracture was performed on the right side of the mandible of each mongrel dogs followed by fixation using resorbable plate fixed with ultrasonic 
welded pins (SonicWeld Rx). They are divided into two groups, the first group was sacrificed after 2 weeks to be examined histologically for early phase of bone healing, and the second group was sacrificed after 6 weeks to be examined histologically for late phase of bone healing.

\section{A) Pre-Operative Phase:}

The selected dogs were kept under the same nutritional and environmental conditions in the animal house at the physiology department, faculty of medicine, Alexandria University.

They were examined by the animal house veterinarian to exclude any disease and were kept on the same balanced diet consisting of milk, broth and meat throughout the whole period.

Each animal received a dose of antibiotic (ampicillin 25 $\mathrm{mg} / \mathrm{Kg}$ body weight) just before the operation to control post-operative infection.

\section{B) Operative Phase:}

All surgeries were performed under sterile conditions in a veterinary operating theatre and was done under general anesthesia. The right submandibular region was shaved with electric clippers, and then scrubbed with betadine surgical scrub solution. The surgical field was isolated with sterile towels clamped to the skin, exposing only the area of surgery. A $5 \mathrm{~cm}$ right submandibular incision was done along the inferior border of the body of the mandible. The periosteum was exposed and incised longitudinally and elevated as high as possible on the lateral aspect of the mandible. An osteotomy cut was made on the lateral surface of the mandible at right angle to the inferior border extending from the buccal to the lingual cortex by using a surgical bur mounted on a low speed hand piece under copious irrigation by $0.9 \%$ sodium chloride solution, then it was continued using an osteotome.

Resorbable plates with ultrasound activated pin osteosynthesis (SonicWeld $\mathrm{Rx}$ ) then placed to fix the fractured segments. Using 4 hole resorbable plate and SonicPin $\mathrm{Rx} 7 \mathrm{~mm}$ length and $2.1 \mathrm{~mm}$ diameter.

Wound debridement was done by normal saline and closure of the wound was performed in layers using 3/0 vicryl suture material then pressure bandages were applied over the sutured wound.

\section{C) Post-Operative Phase:}

All the dogs received intra-muscular injection in the form of ampicillin $25 \mathrm{mg} / \mathrm{Kg}$ body weight for 5 days postoperatively to prevent infection. Analgesics were given to the dogs every 8 hours for the first 2 days.

\section{D) Follow-up Phase:}

The animals were inspected clinically after the first few post-operative days then weekly till the end of follow- up period to assess the general condition and healing of the surgical site and presence or absence of infection or any other complications.

\section{E) Scarification Phase:}

After $2^{\text {nd }}$ and $6^{\text {th }}$ weeks, the dogs were sacrificed with an overdose of thiopentone sodium 2 animals each time. Following euthanasia, mandibles were dissected and preserved by putting them immediately into $10 \%$ neutral buffered formalin for subsequent histological examination.

\section{Histological and histochemical examination:}

Decalcification of the specimen was done, and then processed for cutting and prepared for staining by haematoxylin and eosin (H\&E) and Trichrome stains.
Both histological and histochemical examinations were used to evaluate the healing and resorption at ultrasonic welded pins site.

\section{III- Biomechanical study:}

The biomechanical study was conducted on 15 ribs obtained from one-year-old cows. They were sectioned to simulate fracture and fixed using Resorbable plates with ultrasound activated pin osteosynthesis (Sonic Weld System). They were divided into three groups each consisting of 5 specimens. Group I consisted of 5 specimens tested for tensile stiffness. Group II consisted of 5 specimens tested for bending stiffness. Group III consisted of 5 specimens tested for torsion stiffness (Fig.3).

Ribs were disarticulated and all soft tissues was removed then it was standardized to equal dimensions $8 \mathrm{~cm}$ length and $3 \mathrm{~cm}$ width. They were sectioned with a band saw in a vertical fashion at the midpoint to simulate a fracture. Each sectioned specimen was fixed again together using Resorbable plates with ultrasound activated pin osteosynthesis (Sonic Weld Rx).

INSTRON screw drive universal testing machine was used for testing tensile stiffness and bending stiffness using specially designed test jig for attachment of the specimen.

INSTRON MT torsion testing machine was used for testing torsion stiffness using specially designed test jig for attachment of the specimen.

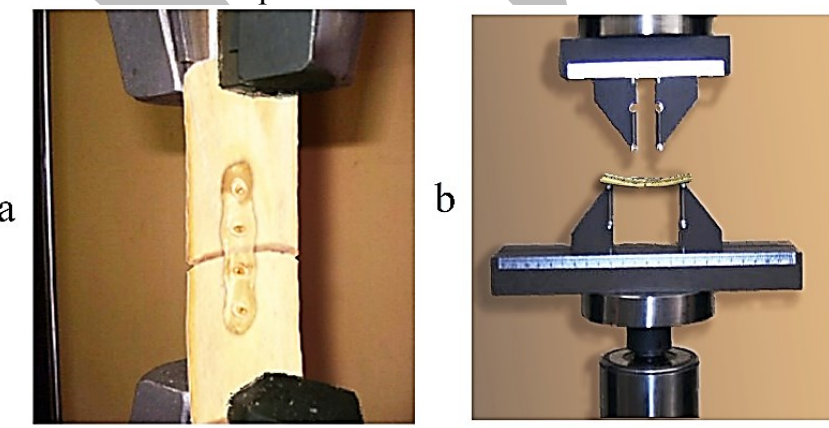

Figure (3): a. Showing specimen attached to jig in Instron universal testing machine for tension testing.

b. Showing specimen placed for bending test in instron universal testing machine.

\section{Methods:}

Each specimen was prepared and stored at $-18^{\circ} \mathrm{C}$ and thawed for 24 hours before testing. In Group I each specimen was attached using specially designed jig to INSTRON universal testing machine then tension force was applied with a constant speed of $5 \mathrm{~mm} / \mathrm{min}$ until fracture occurs. The tensile strength was recorded. In Group II each specimen was attached using specially designed jig to INSTRON universal testing machine then bending force was applied with a constant speed of $5 \mathrm{~mm} / \mathrm{min}$ until fracture or $30^{\circ}$ bending occurs. In Group III each specimen was attached using specially designed jig to INSTRON MT Torsion testing machine then torsion force was applied with a constant speed of $5 \mathrm{~mm} / \mathrm{min}$ until fracture or $160^{\circ}$ torsion occurs.

For all three groups during testing both force and displacement was recorded frequently and graphically presented in force-displacement diagrams. Stiffness was calculated for tensile, bending, and torsion tests by determining the slope of the curve between $25 \%$ and $75 \%$ of Fmax on the force-displacement curves. Stiffness was 
calculated according to equation; $\mathrm{k}=\frac{\mathrm{F}}{\delta}$ Where $\mathrm{k}$ : is the stiffness, $\mathrm{F}$ : is force applied, and $\delta$ : is displacement.

Statistical analysis was descriptive statistics for all resulted data.

\section{RESULTS}

\section{I- Clinical Study Results:}

The patients included in this study were 14 males and 6 females and their ages ranged from 18-40 years with an average of 27.55 years old.

Etiology of fracture was road traffic accidents in $55 \%$ of cases including 7 cases caused by motorcycle accidents and 4 cases caused by car accidents, while physical violence caused $35 \%$ of cases followed by falls representing $10 \%$ of cases in this study.

There were 8 patients with zygomaticomaxillary complex fracture $(40 \%), 4$ patients with bilateral Le Forte type I fracture $(20 \%), 4$ patients with panfacial fracture $(20 \%), 3$ patients with bilateral Le Forte type II fracture (15\%), and 1 patient with zygomatic arch fracture (5\%).

Preoperatively All Patients showed cardinal signs and symptoms of midface fracture including edema, tenderness, step deformity, mobility of fractured segments, and crepitus. The level of consciousness was found to be normal for all patients. Nerve injury with numbness was observed in 13 cases due to injury of the infraorbital nerve fracture line passes along this canal. All cases of Le Forte I, II, and panfacial fracture showed disturbed occlusion. Intraoral mucosal laceration was presented in 7 cases but no uncontrolled bleeding was observed at time of presentation. 8 patients had a tooth involved in the fracture line, but only in 4 patient's extraction of the tooth involved in the fracture line was done due to its root fracture or sever mobility and loss of its vitality. Diplopia was detected preoperatively in all cases of zygomaticomaxillary complex (ZMC), panfacial, and le forteIII fractures. Periorbital ecchymosis also was detected in same cases of diplopia.

All patients of this study were treated within 5 to 15 days after trauma. Patients were treated with open reduction and direct osteosynthesis using resorbable plates with ultrasound activated pin osteosynthesis (Sonic Weld System) Plates were placed along horizontal and vertical buttresses of facial skeleton.

\section{Intraoperative handling evaluation:}

36 pins out of 248 failed to obtain proper fixation and needed to be replaced with other sonic weld pins. This represents $13 \%$ failure rate for the total number of pins placed for all cases together. However, failure rate for each case was found to have mean failure percent as $11.07 \%$ with $\mathrm{SD}=7.079 \%$ (Fig.4).

Time needed for fixation of each plate after proper reduction was calculated using stopwatch and it was found to be 10.625 minutes in average for each plate with SD $=1.56$ minutes.

Stability of the resorbable plate after welding of the pins was recorded. Two cases were found to have poor stability so the decision was made to replace two resorbable plates with ordinary titanium miniplates. Thus failure rate of cases was $10 \%$.

The major difficulty in handling was found in cases with wide displacements, such cases required application of adequate reduction during all the fixation process and any change in position before finishing the fixation of all points led to failure of previously fixed plates. In order to overcome this problem interosseous wiring was done before plate fixation that was then removed after resorbable plate placement and fixation using ultrasonic welded pins.

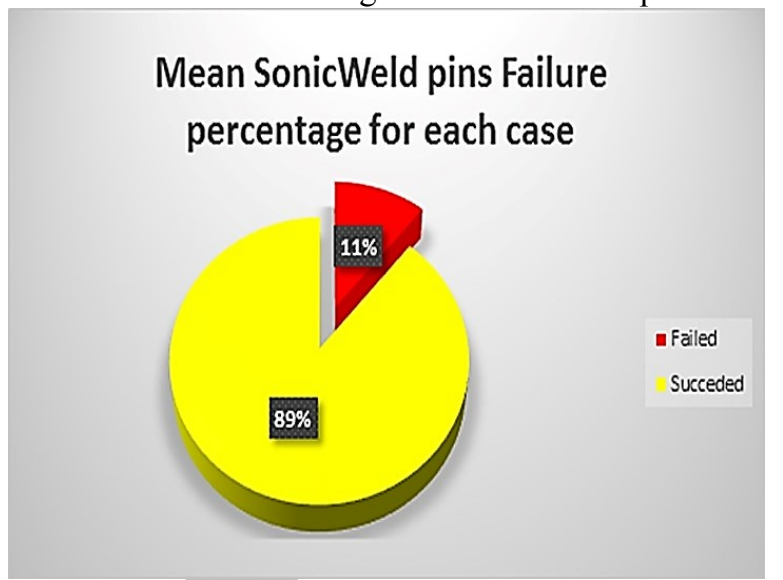

Figure (4): Pie chart showing mean SonicPin $\mathrm{Rx}$ failure percentage for each case.

All cases were examined on the 1st, 3rd, and 6th weeks postoperatively to evaluate presence of edema, presence of infection, presence of pain, stability of fractured segment, occlusal disturbance, presence of abnormal sensation, and any other clinical findings.

There was no major clinical complication postoperatively.

\section{Radiographic results:}

All patients were radiographicaly examined on the 6th week, and 12th week postoperatively using computerized tomography (CT) to evaluate healing at fracture line and at resorbable pins.

Housenfield unit was measured at both fracture line and resorbable pin on the 6 th and 12 th week for each patient and statistically analyzed to evaluate the progress of bone healing at both sites.

There was significant difference in bone density at fracture line between 6th week postoperative CT (Mean $=120.25, \mathrm{SD}=4.59)$ and 12th week postoperative CT $($ Mean $=162.6, \mathrm{SD}=6.73) ; \mathrm{t}(19)=-34.56, \mathrm{p}=.000$ (Table 1$)$

There was significant difference in bone density at pin placement site between 6th week postoperative CT (Mean=100, SD=7.59) and 12th week postoperative CT $($ Mean $=102.35, \mathrm{SD}=7.52) ; \mathrm{t}(19)=-7.023, \mathrm{p}=.000$ (Table 1).

Another paired $t$ test was conducted to compare difference in bone density increase at fracture line and pin placement site between 6th week and 12th week postoperative CT.

There was significant difference in bone density increase between fracture line (Mean $=-42.35, \mathrm{SD}=5.48)$ and pin placement site $($ Mean $=2.35, \mathrm{SD}=1.49) ; \mathrm{t}(19)=-29.99, \mathrm{p}$ $=.000$ (Table 2).

\section{II- Histological Study Results:}

\section{A) Clinical Evaluation:}

All dogs survived the experimental protocol in good health, remained active and alert, and either maintained or gained body weight. The postoperative period went uneventful without complications. Clinical observation indicated that wound had no edema or signs of infection for all dogs.

B) Histological Results:

Early phase of wound healing in Group I (2 weeks): 
The bone-polymer interface site showed proliferation of granulation tissue extravasated by blood corpuscles, blood capillaries, proliferating fibroblasts and fine collagen fibers.

Table 1. Showing paired samples statistics for fracture line healing and pin resorption.

\begin{tabular}{|c|c|c|c|c|c|c|c|c|c|}
\hline \multicolumn{10}{|c|}{ Paired Samples Test } \\
\hline & & \multicolumn{4}{|c|}{ Paired Differences } & \multicolumn{2}{|c|}{$\mathrm{T}$} & \multirow[t]{2}{*}{$\mathrm{df}$} & \multirow[t]{2}{*}{$\mathrm{p}$} \\
\hline & & Mean & \begin{tabular}{|c|} 
Std. \\
Deviation
\end{tabular} & $\begin{array}{c}\text { Std. } \\
\text { Error } \\
\text { Mean }\end{array}$ & $\begin{array}{c}95 \% \\
\text { Confidence } \\
\text { Interval of } \\
\text { the } \\
\text { Difference }\end{array}$ & & & & \\
\hline & & & & & \begin{tabular}{|l|} 
Lower \\
\end{tabular} & Upper & & & \\
\hline $\begin{array}{c}\text { Fracture } \\
\text { Line }\end{array}$ & $\begin{array}{c}6^{\text {th }} \\
\text { week- } \\
12^{\text {th }} \\
\text { week }\end{array}$ & -42.35 & 5.47987 & 1.22534 & -44.9147 & -39.7853 & $3 \mid-34.562$ & 19 & 0 \\
\hline \begin{tabular}{|c} 
Pin \\
Placement \\
Site
\end{tabular} & $\begin{array}{r}6^{\text {th }} \\
\text { week } \\
12^{\text {th }} \\
\text { week }\end{array}$ & -2.35 & 1.49649 & 0.33462 & -3.05038 & -1.64962 & \begin{tabular}{l|l|}
2 & -7.023
\end{tabular} & 19 & 0 \\
\hline
\end{tabular}

Table 2. Showing paired samples statistics for difference between fracture line healing and pin resorption.

\begin{tabular}{|c|c|c|c|c|c|c|c|c|c|}
\hline \multicolumn{10}{|c|}{ Paired Samples Test } \\
\hline & & \multicolumn{5}{|c|}{ Paired Differences } & \multirow[t]{3}{*}{$\mathrm{t}$} & \multirow[t]{3}{*}{$\mathrm{Df}$} & Sig. (2- \\
\hline & & \multirow[t]{2}{*}{ Mean } & \multirow[t]{2}{*}{\begin{tabular}{|c|} 
Std. \\
Deviation
\end{tabular}} & \multirow[t]{2}{*}{$\begin{array}{l}\text { Std. } \\
\text { Error } \\
\text { Mean }\end{array}$} & \multicolumn{2}{|c|}{$\begin{array}{l}95 \% \text { Confidence } \\
\text { Interval of the } \\
\text { Difference }\end{array}$} & & & talled) \\
\hline & & & & & Lower & Upper & & & \\
\hline $\begin{array}{c}\text { Bone } \\
\text { Healing }\end{array}$ & \begin{tabular}{|c|} 
Fracture \\
Line - Pin \\
Placement \\
Site
\end{tabular} & -40 & 5.96481 & 1.33377 & $\begin{array}{c}- \\
42.7916\end{array}$ & \begin{tabular}{|c|} 
\\
37.2084
\end{tabular} & -29.99 & 19 & 0 \\
\hline
\end{tabular}

There were numerous multinucleated giant cells in howship's lacunae. Bone resorption at the periphery was well observed in addition to proliferation of inflammatory cells. The results revealed signs of new bone formation. All bone surface was rimmed by osteoblasts.

Specimens revealed woven bone growing in the defect area and development of new bone, osteocytes and osteoblasts seen on bone surface.

\section{Late phase of wound healing in Group II (6 weeks):}

The examination revealed mild inflammatory cells and proliferation of granulation tissue. The side was invaded by bridge of lamellated bone.

No evidence of osteoclastic activity at bone surface. The regenerated bone was visible replacing the fibrous connective tissue. These showed more advanced calcification than 2 weeks' specimens, the bony trabeculae were oriented longitudinally and bridged the site with small fibrous tissue remained in-between.

The newly formed bone consisted of delicate trabeculae, wide marrow space, primary osteons with numerous osteocytes and osteoblast cells were arranged toward the old bone.

Fusion of new bone lamellated bone with the old one was observed. The mature regenerated new bone was visible bridged most of the gab and in direct contact with the host bone surface demonstrated with deeply stained resting lines. The newly formed bone rimmed by osteoblasts and showed numerous osteocyte cells inclusions consisted of network of lamellar bone trabeculae and marrow spaces. Bony trabeculae of variable thickness and density were also observed. The compact bone revealed normal architecture.

\section{III- Biomechanical Study Results:}

Regarding the side bending test, no fracture at all of either the plate or the pins has been observed. For the tensile as well as the torsion test fracture of the plates was observed regarding the SonicWeld Rx system with no shear or break of SonicWeld Rx pins.

Stiffness was calculated for tensile, bending, and torsion tests.

In Group I tensile stiffness was calculated for all samples and mean tensile stiffness was found to be $498.982 \mathrm{~N} / \mathrm{mm}$ with standard deviation $2.034 \mathrm{~N} / \mathrm{mm}$. In Group II bending stiffness was calculated for all samples and mean bending stiffness was found to be $1.176 \mathrm{~N} / \mathrm{mm}$ with standard deviation $0.92 \mathrm{~N} / \mathrm{mm}$. In Group III torsion stiffness was calculated for all samples and mean torsion stiffness was found to be $0.342 \mathrm{~N} / \mathrm{mm}$ with standard deviation 0.05 N/mm (Fig.5).

From the results obtained there was obvious high tensile stiffness for SonicWeld Rx system with fracture of plates representing the only mode of failure while bending stiffness was obviously low but the mode of failure differed in being liable to plate bending without fracture or shearing of pins. However, in all tests of tension, bending, and torsion fixation of pins to bone was not affected or failed during testing.

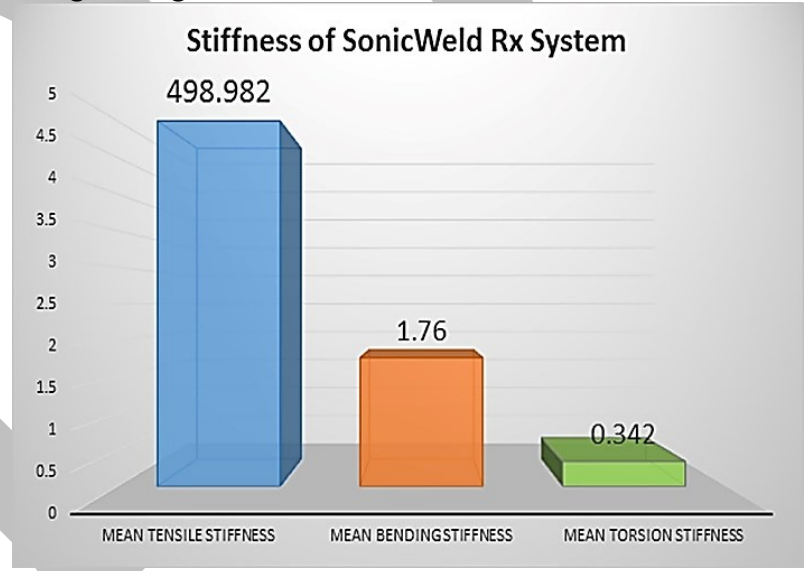

Figure (5): Bar chart showing mean tensile, bending, and torsion stiffness for SonicWeld Rx system.

\section{DISCUSSION}

Use of resorbable materials to stabilize the facial skeleton was first reported more than 40 years ago by Cutright et al. (16) in 1971 since then, it has been shown to be effectively used in craniofacial trauma (17).

The biomechanical study for this system showed that mean tensile stiffness for a resorbable plate fixed fixed using four sonic welded pins was $498.982 \mathrm{~N} / \mathrm{mm}$ with standard deviation $2.034 \mathrm{~N} / \mathrm{mm}$, while mean bending stiffness was $1.176 \mathrm{~N} / \mathrm{mm}$ with standard deviation 0.92 $\mathrm{N} / \mathrm{mm}$, and mean torsion stiffness was $0.342 \mathrm{~N} / \mathrm{mm}$ with standard deviation $0.05 \mathrm{~N} / \mathrm{mm}$.

These results were close to those obtained from Buijs et al. (18) study in 2009 on mechanical strength and stiffness of SonicWeld system which was $496.74 \mathrm{~N} / \mathrm{mm}$ for tensile stiffness, $1.11 \mathrm{~N} / \mathrm{mm}$ for bending stiffness, and $0.32 \mathrm{~N} / \mathrm{mm}$ for torsion stiffness. Their results showed significant difference in stiffness when compared with resorbable plates fixed to bone using ordinary resorbable screws.

Our histological study included early phase of wound healing, 2 weeks after pin welding, which showed no sign of thermally induced damage to the tissue was found, the investigated pathomorphological characteristics were 
within the normal range of adequate bone healing, formation of extracellular matrix was observable at the interface, and no initial signs of polymer resorption were detectable. The regenerated bone was visible replacing the fibrous connective tissue. Late phase of wound healing, 6 weeks after pin welding, showed more advanced calcification than 2 weeks' specimens, the bony trabeculae were oriented longitudinally and bridged the site with small fibrous tissue remained in between.

These findings clearly confirmed Maia et al. (19) study in 2007 which showed that after 2 weeks a tight bonepolymer interlinkage was seen. Neither a pronounced foreign body reaction nor an interposition of fibrous tissue at the interface or a thermally induced necrosis was observed. The late phase of wound healing after 9 weeks showed pathomorphological characteristics within the normal range of bone healing. The bone seemed to be free of any alteration caused by process engineering

Our clinical study included 20 patients with different types of midface fractures $40 \%$ were suffering from zygomaticomaxillary complex fracture, $20 \%$ with Le Forte I fracture, $20 \%$ with panfacial fracture, $15 \%$ with Le Forte II fracture, and 5\% with zygomatic arch fracture. All patients were treated using resorbable plates fixed with ultrasonic welded pins. We used 62 resorbable plate fixed with 248 ultrasonic welded pins.

During fixation of plates 36 pin was failed to fix the plate in position and replaced this represents $13 \%$ failure of total pins used. This failure rate is higher than that was found by Ogbemudia et al. (20) in 2006 who had only $3.4 \%$ failure rate for titanium plate screw fixation.

Reichwein et al. (21) in 2009 had failure rate 5\% (24 pin failures) in pin insertion and welding using the same system presented in this study. They reported these failures to the application of an improper drill, the selection of an improper pin, and improper angulation during insertion. These reasons were found to be identical to our findings in intraoperative handling difficulties of ultrasonic welded pins. The costs associated with repeated use of pins would also likely outweigh the relative cost difference between resorbable and titanium fixation.

Intraoperative stability of fractured segments after welding of pins was examined and we found that there were 2 unstable cases which was $10 \%$ failure rate.

Bell and Kindsfater (22) study in 2006 found 4\% stability failure rate using resorbable plate fixes using resorbable screws. However failed cases in intraoperative stability was related to presence of multiple fractures in two panfacial cases this indicates a limiting factor in using resorbable plates and ultrasonic welded pins.

Mean time needed for placement of each plate was found to be 10 minutes with $\mathrm{SD}=1.56$ minutes, however it was believed in Meara et al. (23) study in 2014 to be no more time-consuming than using titanium miniplates and much more efficient than conventional resorbable screw system because resorbable screws need to be tapped with a separate instrument before insertion. This extra step increases operative time and can make placing the screw at an angle difficult because it is quite sensitive to technique. Thus surgical efficiency with this resorbable fixation technique is enhanced using the ultrasonic-aided pin fixation and may be the greatest advantage of this resorbable system.

Our postoperative clinical findings revealed marked stability in all patients and none of the patients in the current study developed malunion or non-union, and this goes in accordance with Buijs et al. (18) study in 2009, who supported the hypothesis that the principle of fusion of the plate and the pinheads results in better mechanical biodegradable device strength and stiffness.

All cases had no infection signs and symptoms during follow-up period. Edema was within normal range for cases and subsided by the third week postoperatively. These findings correspond with Eckelt et al. (24) study in 2005 on craniofacial fracture fixation using SonicWeld $\mathrm{Rx}$.

Radiolologic examination of the patients involved in this study was done at 6 th and 12 th week postoperatively. It showed properly aligned fracture segments and there were no bony resorption or rarefaction around the plates or pins.

These findings were compatible with El-Saadany et al. (25) study in 2015 that showed progressively noticed healing of the fractures although the persistence of the radiologically detected holes after 3 months representing pin placement sites. However, it did not affect the stability of the fracture or healing.

Our radiographic results were also conforming to Reichwein et al. (21) findings in 2009 on their study on panfacial fracture fixation using resorbable plate with ultrasonic welded pins.

From the statistical results we concluded that SonicWeld $\mathrm{Rx}$ system offered proper fixation that allowed proper healing at fracture line meanwhile pin placement site had less bone density due to delayed resorption of pins however this delayed resorption guaranteed sustained fixation till the process of healing was commenced at fracture lines. This was in consistent with Buijs et al. (18) in 2009 who stated that, due to the welding technique, the mechanical properties are greatly enhanced.

\section{CONCLUSIONS}

The analysis of the clinical, radiographic, histological, and biomechanical results of the current study, proved that, ultrasound based welding process by (Sonic weld Rx) for fixation of PDLLA plates and pins was effective in midface fractures.

\section{CONFLICT OF INTEREST}

The authors declare that they have no conflicts of interest.

\section{REFERENCES}

1. Greenberg AM, Prein J. Craniomaxillofacial reconstructive and corrective bone surgery. First edition, Springer: New York. 2002. p. 317-26.

2. Pietrzak WS. Critical concepts of resorbable internal fixation. J Craniofac Surg.2000; 11:335-6.

3. Ueki K, Hashiba Y, Marukawa K, Okabe K, Nakagawa K, AlamS, et al. Evaluation of Bone Formation After Sagittal Split Ramus Osteotomy with Bent Plate Fixation Using Computed Tomography. J Oral Maxillofac Surg. 2009; 67:1062-8.

4. Barry L, Eppley M. Repair of midfacial fractures with resorbable plates and screws, Oper Techn OtolaryngologyHead Neck Surg. 2002;13:287-92.

5. David E, Vázquez M, Donita DS, Stewart K, Lazow T, Julius R. Treatment of mandible fractures using resorbable 
plates with a mean of 3 weeks maxillomandibular fixation: a prospective study. J O Surg O Med O Path O Rad Endon. 2013;115: 25-8.

6. Wood RJ, Petronio JA, Graupman PC, Shell CD, Gear AJ. New resorbable plate and screw system in pediatric craniofacial surgery. J Craniofac Surg. 2012;23(3):845-9.

7. Yerit KC, Enislidis G, Schopper C, Turhani D, Wanschitz F. Fixation of mandibular fractures with biodegradable plates and screws. J Oral Surg Oral Med Oral Pathol Oral Radiol. 2002; 94:294-300

8. Hammond D, Parmar S. A Review of the Use of Resorbable Plateing Systems in Cranio-Maxillofacial Surgery. J Trop Med Surg. 2013; 1:151-4.

9. Eppley BL, Morales L, Wood R. Resorbable PLLA-PGA plate and screw fixation in pediatric craniofacial surgery: clinical experience in 1883 patients. J Plast Reconstr Surg. 2004; 114:850-6.

10. Neff A, Muhlberger G, Karoglan M. Stability of osteosyntheses for condylar head fractures in the clinic and biomechanical simulation. J Mund Kiefer Gesichtschir. 2004; 8:63-74.

11. Ricalde P, Engroff SL, Von Fraunhofer JA, Posnick JC. Strength analysis of titanium and resorbable internal fixation in a mandibulotomy model. J Oral Maxillofac Surg. 2005; 63:1180-3.

12. Wittwer G, Adeyemo W L. An evaluation of the clinical application of three different biodegradable osteosynthesis materials for the fixation of zygomatic fractures. J O Surg O Med O Path O Rad Endon. 2005;100(6):656-60.

13. Carron M A, Zuliani G. Stability of midface fracture repair using absorbable plate and screw system pilot holes drilled and pin placement at angles other than $90^{\circ}$. J Facial Plast Surg. 2014;16(1):42-8.

14. Cho P, Burton R, Gratton D, Cho H. Biomechanical study of SonicWeld $\mathrm{Rx}$ pin in cortical bone graft layering technique. J Oral Maxillofac Surg. 2011; 69:1519-22.

15. Pilling E, Meissner H, Jung R, Kochd R, Loukota R, Maia R, Reitemeier B, Richter G, Stadlinger B, Stelnicki E, Eckelt U. An experimental study of the biomechanical stability of ultrasound-activated pinned (SonicWeld $\mathrm{Rx}{ }^{\circledR}+$ Resorb-X®) and screwed fixed (Resorb-X®) resorbable materials for osteosynthesis in the treatment of simulated craniosynostosis in sheep. $\mathrm{Br} \mathrm{J}$ Oral Maxillofac Surge. 2007;45:451-6.

16. Cutright DE, Hunsuck EE, Beasley JD. Fracture reduction using a biodegradable material, polylactic acid. J Oral Surg. 1971; 29:393-7. Quoted from Kontakis G, Pagkalos J, Tosounidis T, Melissas J, Katonis P. Bioabsorbable materials in orthopaedics. Acta Orthop. 2007; 73:159-69.

17. Mc Leod N M, Saeed N R. Treatment of fractures of the mandibular condylar head with ultrasound-activated resorbable pins: early clinical experience. $\mathrm{Br} \mathrm{J}$ Oral Maxillofac Surg. 2016; 54:872-7.

18. Buijs GJ, van der Houwen EB, Stegenga B, Verkerke GJ, Bos RR. Mechanical strength and stiffness of the biodegradable SonicWeld Rx Osteofixation System. J Oral Maxillofac Surg. 2009; 67:782-90.

19. Maia R., Lauera G, Pilling E, Jungc R, Leonhardta H, Proff $\mathrm{P}$ Et al. Bone welding - A histological evaluation in the jaw. Ann. Anatomy J. 2007;189(4):350-5.

20. Ogbemudia AO, Phillip FA. Umebese SA. Implant failure in osteosynthesis of fractures of long bones. J Medic Biomed Resear. 2006; 5:75-8.
21. Reichwein AM, Schicho KD, Moser DS, Seemann RO, Poeschl PA, Baumann SA et al. Clinical Experiences with Resorbable Ultrasonic-Guided, Angle-Stable Osteosynthesis in the Panfacial Region. J Oral Maxillofac Surg. 2009; 67:1211-7.

22. Bell RB, Kindsfater CS. The use of biodegradable plates and screws to stabilize facial fractures. J Oral Maxillofac Surg. 2006; 64:31-9.

23. Meara D, Knoll M, Holmes J, Clark M. Fixation of Le Fort I Osteotomies with Poly-DL-Lactic Acid Mesh and Ultrasonic Welding-A New Technique. J Oral Maxillofac Surg. 2014; 70:1139-44.

24. Eckelt U, Pilling E, Stelnicki E: A new resorbable fixation technique in craniofacial surgery. Int $\mathrm{J}$ Oral Maxillofac Surg. 2005; 34:84-90.

25. El-Saadany W H, Sadakah A A, Hussein M M, Saad K A. Evaluation of using ultrasound welding process of biodegradable plates for fixation of pediatric mandibular fractures. Tanta Dent J. 2015; 12:22-9. 